ment. Patients with Hodgkin's disease in the spleen represent a high-risk group for concomitant or subsequent hepatic and marrow disease $\mathbf{2}^{3}$ and are therefore candidates for combined radiotherapy and chemotherapy. The high correlation of splenic disease with positive liver and marrow findings is also emphasised by our results. Therefore laparotomy is indicated in Hodgkin's disease not only to confirm or exclude liver disease but also to show the presence of an otherwise occult splenic lymphoma. For this reason we attempted to explore the yield of splenic biopsies through laparoscopy and found that this procedure detected infiltration by lymphoma in about one-third of patients with diseased spleens.

The relative merits of laparoscopy and laparotomy should also be compared in terms of the morbidity of each procedure. Laparotomy caused more complications than laparoscopy. Two patients in each group required exploratory laparotomy for episodes directly related to the staging procedure. Splenectomy also increases the incidence of varicella-zoster infection, especially in patients undergoing combination chemotherapy, and may be followed in few patients by fulminant infections. ${ }^{4}$ Laparoscopy, besides being devoid of such complications, may reduce the stay in hospital. ${ }^{5}$

In conclusion, laparoscopy plus needle marrow biopsy in
Hodgkin's disease could replace the traditional exploratory laparotomy with splenectomy and multiple tissue biopsies in at least two-thirds of patients with extranodal disease and in about one-third of those with splenic disease. All patients should therefore be subjected to this combined procedure as a screening technique for pathological staging and restaging before undergoing laparotomy. Exploratory laparotomy remains an accepted and necessary procedure only for patients negative on preoperative laparoscopy and needle marrow biopsy. Splenic biopsy during peritoneoscopy should no longer be considered an almost invariably hazardous procedure except in patients with a large and congestive spleen.

Requests for reprints should be addressed to: Dr Gianni Bonadonna, Istituto Nazionale Tumori, Via Venezian, 1-Milano 20133, Italy.

\section{References}

${ }^{1}$ Bagley, C M, jun, et al, Cancer, 1973, 31, 840.

2 Kaplan, H S, et al, National Cancer Institute Monographs, 1973, 36, 291.

${ }^{3}$ Veronesi, U, et al, Cancer, 1974, 33, 446.

${ }^{4}$ Monfardini, S, et al, Cancer, 1975, 11, 51 .

5 Sugarbaker, P H, et al, Lancet, 1975, 1, 442.

\title{
Weight gain and the sleeping electroencephalogram: study of 10 patients with anorexia nervosa
}

\author{
J H LACEY, A H CRISP, R S KALUCY, M K HARTMANN, C N CHEN
}

British Medical fournal, 1975, 4, 556-558

\section{Summary}

The relation between reduced nutritional intake, with consequent weight loss, and sleep disturbance was studied by comparing certain sleep encephalogram patterns in a group of inpatients with anorexia nervosa before, during, and after a regimen of refeeding with a normal diet to a matched population mean weight. At low body weights patients had less sleep and more restlessness, especially in the last four hours of the night. During refeeding and weight gain slow-wave sleep initially increased and then tended to decrease during the final stage of restoration of weight back to matched population mean levels. With the overall weight gain, however, there was a significant increase in length of sleep and rapid eye movement sleep, the latter increasing especially during the later stages of weight gain. These results reaffirm that insomnia, and especially early morning waking, is associated with low body weight in anorexia nervosa, and their implications are discussed with particular reference to a hypothetical association between various anabolic profiles and the need for differing components of sleep.

\footnotetext{
Academic Department of Psychiatry. St George's Hospital Medical School, London SW17

J H LACEY, MPHIL, MRCPSYCH, research fellow

A H CRISP, MD, FRCPSYCH, professor of psychiatry

R S KALUCY, FRACP, MRCPSYCH, senior lecturer

M K HARTMANN, BA, research assistant

C N CHEN, MSC, MRCPSYCH, research fellow
}

\section{Introduction}

Patients with anorexia nervosa have a pattern of sleep different from that of most young people. They tend to have disturbed sleep in the middle third of the night and to wake early. This disturbance is unrelated to mood but is probably related to the severity of the nutritional disturbance. ${ }^{1}$ When the weight of such patients is restored to normal in association with bed rest and a normal diet the sleep pattern reverts to normal; these changes are again unrelated to mood. Conversely, obese people losing weight on a diet begin to sleep less, especially in the second half of the night.' Admittance to hospital, like mood and mood change, does not seem to affect these changes. It has also been shown ${ }^{3}$ that, irrespective of diagnosis, mentally ill patients who lose weight because of their illness also sleep less, especially in the second half of the night; in particular they experience more sleep interruptions, longer periods of interrupted sleep, and earlier waking. Among those who gain weight the converse is true.

Excessive somnolence is a recognised accompaniment of the Kleine-Levin syndrome, ${ }^{4}$ the syndrome of megaphagia and hypersomnia, ${ }^{5}$ and, more debatably, the Pickwickian syndrome. ${ }^{6}$ Eating is a recognised precipitant of some narcolepsy attacks. ${ }^{7}$ Recently it has been shown that a bedtime milk cereal drink leads to an increase in sleep, especially in the second half of the night. ${ }^{8}{ }^{9}$

We report here a study of the sleeping electroencephalogram (EEG) changes associated with aspects of nutritional and weight change in patients with anorexia nervosa. A preliminary study of five patients showed that it was predominantly slow-wave sleep that was increased when the weight of such patients was restored towards normal. Most of these patients failed to achieve matched population mean weights, however, and their refeeding diets were often high in protein and fat and low in carbohydrate. ${ }^{10} \mathrm{We}$ expected therefore that we would once again find a positive association between weight gain and increased sleep; 
but the qualitative nature of this increase remained to be explored.

\section{Patients and methods}

Ten patients (nine women and one man) with unequivocal evidence of primary anorexia nervosa were studied. They were consecutive admissions to the inpatient psychiatric unit at Atkinson Morley's Hospital.

They were all "abstainers"; thus their dietary pattern was one of restricted food intake, especially of carbohydrate, and not one of indiscriminate overeating and vomiting. None showed evidence of major haematological or electrolytic abnormality. Routine chest $x$-ray films were "clear" and none of the patients had a history of epilepsy. We intended that they should receive no medication after admission, but one patient had been placed on a major tranquilliser (chlorpromazine) before admission and another became so disturbed on admission that similar treatment was deemed necessary. Both remained on this medication throughout the study.

Each patient was prescribed a diet of $12.5 \mathrm{MJ}(3000 \mathrm{kcal})$ a day containing normal amounts of carbohydrate. From the time of admission the meals more or less conformed to usual hospital meals, but patients also received supplements in the form of cheese sandwiches and biscuits with their afternoon tea. This diet was intended to generate a weight increase of $1 \cdot 1-1 \cdot 6 \mathrm{~kg}$ a week. ${ }^{11} \mathrm{~A}$ weight change outside these limits led to a review of diet and an appraisal of the patient's eating behaviour. The target weight was calculated from standard tables, based on the population mean weight for the patient's height at the age when his or her illness began. Patients were restricted to bed rest in individual cubicles until they reached their target weight. This restriction extended to eating and washing although they were allowed to use a commode. Occupational therapy was of a sort that did not lead to undue energy expenditure. They and their families were involved in psychotherapy from the beginning.

After the patients had had time to become accustomed to their new environment the first recording period began. It was never later than 12 days after admission. Six patients (cases 3, 4, 6-8, and 10) had a second recording session when at $15^{\circ}$, below their target weight and all 10 patients were re-recorded when they had reached their target weight. The recordings at the sub-target weight $\left(15^{\circ}\right.$, below) reflected an attempt to tap cerebral electro-physiological events at a time known in these patients to be associated with major endocrine changes of a "pubertal" kind.11"

Nine electrodes were used in the classical manner described by Rechtschaffen and $\mathrm{Kales}^{15}$ to produce two electro-occulogram recordings, one scalp EEG, and one electromyogram. The two occipital placements used corresponded to positions $\mathrm{C} 3$ and $\mathrm{C} 4$ in the 10-20 system of electrode placement. The recording was started at 2300 and lasted for at least seven hours or until the patient spontaneously awoke. The recordings were examined by an investigator who was unaware of the order in which they were obtained. Depth of sleep was rated for each 20 -second period throughout the night. The recordings were scored according to the internationally agreed criteria into stages $1,2,3,4$, rapid eye movement $(\operatorname{REM})(5)$, and awake $(0)$.

\section{Results}

The mean age of the patients was $17 \cdot 3 \pm 3 \cdot 13$ years (table I). The overall mean weight gain was $15.25 \mathrm{~kg}$, the mean gain between admission and second recording session $(7.5 \mathrm{~kg})$ being similar to that between the second and target weight recordings $(7.75 \mathrm{~kg})$.

\section{SLEEP CHANGES}

Some overall changes in sleep are shown in table II.

Total sleep time-Patients spent more time asleep when they were heaviest (table II ; $t=4.55 ; \mathrm{DF}=9 ; \mathrm{P}<0.005$; one-tailed test of paired observations). Total sleep time included time spent awake after the initial onset of sleep and before final waking. If only the time spent actually asleep was considered the increase in mean sleep time was greater still. This increase in sleep occurred particularly during the period of final weight gain $(t=3.01 ; \mathrm{DF}=5 ; \mathrm{P}<0.025$; one-tailed test). Thus, in the subgroup of six the average increase in total sleep was only four minutes between admission and the second recording, but the total sleep time increased from 394.4 minutes to $441 \cdot 7$ minutes between the second and target recordings. The mean weight increase between the first and second recording periods $(19.9 \%)$ was if anything larger than that between second and target recordings $(17.5 \%)$, yet the major increase in total sleep time occurred only as the patient approached target weight.

TABLE I-Ages and weights of 10 patients at three recording periods

\begin{tabular}{|c|c|c|c|c|c|}
\hline \multirow{2}{*}{ Case No } & \multirow{2}{*}{$\left|\begin{array}{c}\text { Age } \\
\text { (years) }\end{array}\right|$} & \multicolumn{3}{|c|}{ Weight $(\mathrm{kg})$ at: } & \multirow{2}{*}{$\begin{array}{l}\text { No of lapsed } \\
\text { days between } \\
\text { 1st and targe } \\
\text { recordings }\end{array}$} \\
\hline & & $\begin{array}{c}\text { First } \\
\text { recording }\end{array}$ & $\begin{array}{l}15 \% \text { below } \\
\text { target weight }\end{array}$ & $\begin{array}{c}\text { At } \\
\text { target weight }\end{array}$ & \\
\hline $\begin{array}{r}1 \\
2 \\
3 \\
4 \\
5 \\
6 \\
7 \\
8 \\
9 \\
10\end{array}$ & $\begin{array}{l}16 \\
21 \\
24 \\
17 \\
16 \\
15 \\
14 \\
20 \\
16 \\
14\end{array}$ & $\begin{array}{l}36 \cdot 4 \\
39 \cdot 9 \\
44 \cdot 5 \\
28 \cdot 2 \\
39 \cdot 0 \\
38 \cdot 2 \\
45 \cdot 0 \\
30 \cdot 0 \\
38 \cdot 8 \\
35 \cdot 6\end{array}$ & $\begin{array}{l}\overline{-} \\
47 \\
38 \cdot 8 \\
\overline{42 \cdot 9} \\
50 \cdot 1 \\
37 \cdot 7 \\
4 \overline{48 \cdot 7}\end{array}$ & $\begin{array}{l}50 \cdot 7 \\
54 \cdot 9 \\
54 \cdot 8 \\
45 \cdot 5 \\
54 \cdot 0 \\
50 \cdot 1 \\
59 \cdot 2 \\
44 \cdot 6 \\
48 \cdot 8 \\
57 \cdot 5\end{array}$ & $\begin{array}{r}76 \\
117 \\
68 \\
72 \\
112 \\
93 \\
110 \\
96 \\
90 \\
174\end{array}$ \\
\hline Mean of 10 & $17 \cdot 3$ & $37 \cdot 5$ & - & $52 \cdot 0$ & $100 \cdot 8$ \\
\hline Mean of 6 & $17 \cdot 3$ & $36 \cdot 9$ & $44 \cdot 2$ & $52 \cdot 0$ & $102 \cdot 2$ \\
\hline
\end{tabular}

TABLE II-Mean time (minutes) in each stage of sleep before and after restoration of weight in 10 patients

\begin{tabular}{c|c|c|c}
\hline Stage & $\begin{array}{c}\text { At admission } \\
\text { weight }\end{array}$ & $\begin{array}{c}\text { At target } \\
\text { weight }\end{array}$ & $\begin{array}{c}\text { Significance } \\
(\mathrm{P})\end{array}$ \\
\cline { 1 - 3 } Awake & 26.72 & $6 \cdot 76$ & $<0 \cdot 05$ \\
1 & 14.43 & 12.64 & $\mathrm{NS}$ \\
3 & 170.00 & 183.40 & $\mathrm{NS}$ \\
4 & 28.80 & 32.10 & $\mathrm{NS}$ \\
$3+4$ & 46.10 & $51 \cdot 20$ & $\mathrm{NS}$ \\
REM & 74.90 & 83.32 & $\mathrm{NS}$ \\
\hline Total sleeping time & 100.85 & 141.08 & $<0.001$ \\
\hline & 386.90 & 427.20 & $<0.005$ \\
\hline
\end{tabular}

Patterns of wakefulness (sleep stages 0 and 1)-The figure shows the marked decrease in wakefulness with refeeding $(t=1.96 ; \mathrm{DF}=6$; $\mathrm{P}<0.05$; one-tailed test), and further suggests that wakefulness at low body weights was concentrated towards the end of the sleeping period. Table III deals with the last four complete hours of recording in each patient in the three recording periods. The six subjects in the subgroup were already less disturbed by early morning waking and restlessness (stages $0+1$ ) when their weight had risen to within $15 \%$ of target level. In the total group wakefulness and restlessness were both significantly reduced $(P<0.05)$ after full restoration of weight.

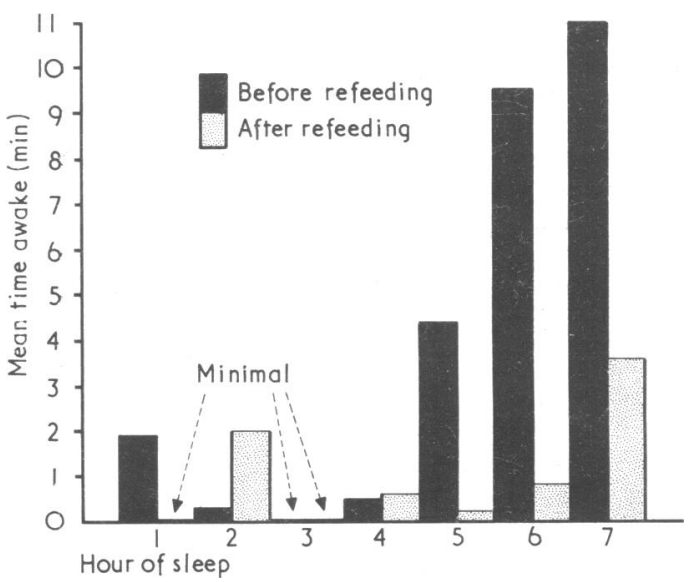

Mean time spent awake for each hour of night before and after refeeding.

Deep sleep (slow-wave sleep; stages 3 and 4)-Table IV shows that the amount of slow-wave sleep was significantly increased $(t=3.23$; $\mathrm{DF}=5 ; \mathrm{P}<0.05$; two-tailed test) as weight increased to sub-target level and then tended to fall $(t=2.38 ; \mathrm{DF}=5 ; \mathrm{P}<0.1$; two-tailed 
test) as the patient reached a stable weight level. The increase in slowwave sleep overall was not significant though with increasing weight the patients tended to spend more time in deep sleep ( 8.42 minutes more) and also stage 2 non-REM sleep (13.4 minutes more) (table II).

TABLE III-Mean time (minutes) spent awake (stage 0 ) and in state of restlessness (stages $0+1$ ) in last four complete hours of recording before, during, and after weight gain

\begin{tabular}{|c|c|c|c|c|}
\hline & \multicolumn{2}{|c|}{ Mean of 10} & \multicolumn{2}{|c|}{ Mean of 6} \\
\hline & 0 & $0+1$ & 0 & $0+1$ \\
\hline $\begin{array}{l}\text { Admission } \\
\text { When } 15 \% \text { o below target weight } \\
\text { At target weight } \ldots \quad \ldots \quad \ldots\end{array}$ & $\begin{array}{r}23 \cdot 8 \\
2 \cdot 9\end{array}$ & $\begin{array}{r}31 \cdot 2 \\
8 \cdot 3\end{array}$ & $\begin{array}{r}30 \cdot 6 \\
5 \cdot 4 \\
2 \cdot 4\end{array}$ & $\begin{array}{r}36 \cdot 3 \\
20 \cdot 0 \\
6 \cdot 0\end{array}$ \\
\hline
\end{tabular}

TABLE IV-Amount of slow-wave sleep (stages $3+4$ ) at increasing weights in six patients with anorexia nervosa

\begin{tabular}{|c|c|c|c|}
\hline \multirow{2}{*}{ Case No } & \multicolumn{3}{|c|}{ Slow-wave sleep (minutes) at: } \\
\hline & Admission & $\begin{array}{l}15^{\circ} \text {, below } \\
\text { target weight }\end{array}$ & Target weight \\
\hline $\begin{array}{r}3 \\
4 \\
6 \\
7 \\
8 \\
10\end{array}$ & $\begin{array}{l}13 \cdot 3 \\
78.6 \\
91 \cdot 1 \\
96 \cdot 6 \\
22.4 \\
52 \cdot 0\end{array}$ & $\begin{array}{r}136.7 \\
154.0 \\
101.4 \\
120 \cdot 3 \\
64.7 \\
102.3\end{array}$ & $\begin{array}{r}58.6 \\
91.4 \\
73.6 \\
111.4 \\
29.7 \\
116.7\end{array}$ \\
\hline Mean & $58 \cdot 8$ & $113 \cdot 2$ & $86 \cdot 2$ \\
\hline \multirow[t]{2}{*}{ Significance } & & \multicolumn{2}{|c|}{$P<0 \cdot 1$} \\
\hline & \multicolumn{3}{|c|}{ NS } \\
\hline
\end{tabular}

REM sleep-REM sleep increased significantly $(t=5.92 ; \mathrm{DF}=9$; $\mathrm{P}<0.001$; two-tailed test) by about $40 \%$ overall (table II), and examination of the subgroup of six showed that the mean total REM time increased from 99 minutes on admission to 109 minutes at $15 \%$ below target weight and 139 minutes at full target weight. Although REM sleep tends to accumulate in the second half of the night this increase in REM sleep was not due simply to the increase in the length of time spent asleep at higher body weights. REM sleep still increased by $27 \%$ when a correction was made for this increased total sleep time.

\section{Discussion}

Previous studies have established that the sleep disturbance in the latter part of the night that characterises the state of starvation found in anorexia nervosa is corrected by refeeding, which promotes weight back to normal. We examined in detail aspects of the electrophysiological nature of such sleep and sleep change. Anorectic patients can often be usefully divided into those who abstain from eating, in whom the predominant dietary restriction is of carbohydrate, and those who overeat and vomit or purge, or both, albeit secretly, and whose state then reflects a more general dietary and electrolyte depletion. ${ }^{11} 14$ The metabolic status of the two groups is quite distinct and the latter group is more prone to display symptomatic epilepsy and generalised EEG disturbance during wakefulness. ${ }^{15}$ The sleep disturbance, however, seems to characterise both groups equally. ${ }^{1}$ All our patients had avoided eating and hence had related carbohydrate starvation. A high carbohydrate diet is associated with an increase in REM sleep in normal people. ${ }^{16}$ Certainly our patients, having been starved of carbohydrate, received diets relatively high in carbohydrate content as part of their treatment and in this respect they differed from other anorectic patients studied, ${ }^{10}$ who tended to eat high fat/protein diets as part of their treatment and who, although they achieved substantial weight gains and an associated increase in slow-wave sleep, did not always achieve a final weight strictly at the matched population mean level. This latter factor may also be important since the main increase in REM sleep displayed by our patients occurred after they had achieved a mean weight of just over $44 \mathrm{~kg}$ and during the period when they gained weight up to strictly matched population mean levels-that is, a further mean weight gain of about $8 \mathrm{~kg}$ for the group.

It is at this intermediate weight level of around $44 \mathrm{~kg}$ that a similar group of "abstaining" anorectics have been found to display a change in pituitary responsiveness to luteinising hormone/ follicle-stimulating hormone-releasing hormone. ${ }^{12}$ At this weight there is also a shift in the metabolic rate in such patients. ${ }^{1417} \mathrm{It}$ has been suggested that these changes reflect the rekindling of the "pubertal" process and, presumably, include important changes in cerebral activity, which we were trying to tap by investigating our patients at this weight as well as above and below it. The reduction in slow-wave sleep found as our patients gained weight above the $44 \mathrm{~kg}$ threshold can be reconciled with the findings of MacFadyen et al. ${ }^{18}$ They found an increase in slow-wave sleep and what they took to be a secondary decrease in REM sleep in normal people starved for a brief period, during which they lost an average of $5 \mathrm{~kg}$. Such a weight loss, operating above the "pubertal" threshold, produced sleep EEG changes in their subjects opposite to those arising in our patients as their weight rose through the same range.

In summary, the characteristics of and the changes in EEG sleep patterns in patients with anorexia nervosa who are admitted in a starved state and at a low weight and whose weight is then restored to matched population mean levels seem to arise in two distinct phases of weight gain. On admission and before refeeding there is gross reduction in both slow-wave sleep and REM sleep in association with reduced total sleeping time. As weight is initially gained and sleep increases this is largely an increase of slow-wave sleep, while REM sleep also increases. It has been suggested $^{19}$ that slow-wave sleep is associated with general bodily synthetic processes, and such processes evidently characterised our patients at this stage. After further weight restoration, and after what has been seen in comparable patients to be a shift in metabolism in association with restoration of aspects of reproductive physiology and, presumably, a related increase in cerebral activity, REM sleep is selectively increased and slow-wave sleep declines. Oswald ${ }^{19}$ has also suggested that REM sleep may relate specifically to cerebral synthetic processes. While any comprehensive interpretation of our findings must remain speculative they do not contradict Oswald's views and may lend some support to them.

\section{References}

1 Crisp, A H, Fournal of Psychosomatic Research, 1967, 11, 117.

2 Crisp, A H, and Stonehill, E, Fournal of Psychosomatic Research, 1970, 14, 327

3 Crisp, A H, and Stonehill, E, British fournal of Psychiatry, 1973, 122, 379.

${ }^{4}$ Levin, M, Archives of Neurology and Psychiatry, 1929, 22, 1172.

5 Cutting, W C, Stanford Medical Bulletin, 1944, 2, 172.

6 Burwell, C S, et al, American fournal of Medicine, 1956, 21, 811.

7 Daniels, L E, Medicine, 1934, 13, 1.

8 Brezinova, V, and Oswald, I, British Medical fournal, 1972, 2, 431.

9 Southwell, P R, Evans, C R, and Hunt, J N, British Medical fournal, 1972, $2,429$.

${ }^{10}$ Crisp, A H, Stonehill, E, and Fenton, G W, Psychotherapy and Psychosomatics, 1970, 18, 161 .

11 Crisp, A H, Hospital Medicine, 1966/1967, 1, 713.

12 Palmer, R L, et al, British Medical fournal, 1975, 1, 179.

13 Rechtschaffen, A, and Kales, A, (editors), Manual of Standardised Terminology, Techniques and Scoring System for Sleep Stages of Human Subjects. Bethesda, National Institutes of Health, 1968.

14 Crisp, A H, World Review of Nutrition and Dietetics, 1970, 12, 452.

15 Crisp, A H, Fenton, G W, and Scotton, L, British fournal of Psychiatry, $1968,114,1149$

16 Phillips, F, et al, Lancet, 1975, 2, 723.

17 Crisp, A H, and Kalucy, R S, Postgraduate Medical fournal, 1973, 49, 883.

18 MacFadyen, U M, Oswald, I, and Lewis, S A, Fournal of Applied Physiology, 1973, 35, 391.

19 Oswald, I, New Scientist, 1970, 23, 170. 